\title{
Digestão Simulada de Bebida Esportiva Contendo Diferentes Probióticos
}

\section{Simulated Digestion of Sports Drink Containing Different Probiotics}

\author{
Luciana de Carvalho Finoa; Fabíola de Lima Pena ${ }^{a}$; Maria Carolina Pelatieri Rodrigues do Vallea; Thais Ramos da \\ Silva ${ }^{a}$; Vivian Cristina da Cruz Rodrigues ${ }^{\text {a }}$, Adriane Elisabete Costa Antunes*a
}

aUniversidade Estadual de Campinas, Faculdade de Ciências Aplicadas. SP, Brasil.

*E-mail: adriane.antunes@fca.unicamp.br

\begin{abstract}
Resumo
O exercício físico de alta intensidade está relacionado com diversas alterações sistêmicas que podem prejudicar a performance do indivíduo, tais como: a queda da imunidade, a perda de massa muscular, a insônia, entre outros. Os probióticos, quando administrados regularmente para esse público, podem reduzir os sintomas relacionados ao overtraining. O presente estudo buscou selecionar uma cepa probiótica para empregar em uma bebida esportiva (a base de leite fermentado), contendo elevada quantidade de compostos fenólicos e adicionada de cepas probióticas, sendo utilizadas como principal critério de escolha a sobrevivência da mesma após digestão simulada. Foram avaliados os probióticos Lactobacillus casei (BGP93), Lactobacillus rhamnosus (SP1) e Lactobacillus acidophilus (LA3) e Bifidobacterium animalis subsp. lactis (BB12), utilizando-se como cultura starter o Streptococcus thermophilus (TA072). Em paralelo foi realizada avaliação da resistência das culturas probióticas em solução adicionada de suco de romã, tendo em vista a potencial atividade antimicrobiana desta fruta. Neste teste foi observado que as culturas probióticas não foram inibidas pelo suco de romã, com exceção do L. acidophilus LA3. Para digestão in vitro foi utilizado protocolo validado composto pelas fases gástrica e entérica, a viabilidade dos probióticos na bebida esportiva foi acompanhada durante armazenamento refrigerado a $6{ }^{\circ} \mathrm{C}$ por 28 dias e a sobrevivência foi avaliada, por meio de contagem seletiva em DeMan, Rogosa \& Sharpe (MRS) ágar acidificado e incubação em anaerobiose. Os resultados demonstraram que o Lactobacillus casei cepa BGP93 apresentou adequada viabilidade durante o armazenamento e maior taxa de sobrevivência à digestão, quando comparado aos demais probióticos, representando um bom candidato para a elaboração da bebida esportiva.
\end{abstract}

Palavras chave: Leite Fermentado. Compostos Fenólicos. Alimento Funcional. Viabilidade de Probióticos.

\begin{abstract}
High-intensity physical exercise is related to several systemic alterations that may impair the individual's performance, such as immunity depletion, muscle mass loss, insomnia, among others. Probiotics, when given regularly to this public, may reduce symptoms related to overtraining. The present study aimed to select a probiotic strain for use in a sports drink (based on fermented milk) containing a high amount of phenolic compounds, and added probiotic strains, being the main criterion of choice the survival of the strain after simulated digestion. The probiotics Lactobacillus casei (BGP93), Lactobacillus rhamnosus (SP1) and Lactobacillus acidophilus (LA3) and Bifidobacterium animalis subsp. lactis (BB12), using as starter culture Streptococcus thermophilus (TA072). At the same time, resistance evaluation of probiotic cultures in pomegranate juice solution was carried out, considering the potential antimicrobial activity of this fruit. In this test, it was observed that probiotic cultures were not inhibited by pomegranate juice, except for L. acidophilus LA3. For in vitro digestion a validated protocol consisting of gastric and enteric phases was used, the viability of probiotics in the sports drink was monitored during cold storage at $6^{\circ} \mathrm{C}$ for 28 days and survival was evaluated by selective counting in acidified DeMan, Rogosa \& Sharpe (MRS) agar and incubation in anaerobiosis. The results showed that Lactobacillus casei strain BGP93 showed adequate viability during storage and higher survival rate to digestion when compared to other probiotics, representing a good candidate for the sport drink preparation
\end{abstract}

Keywords: Fermented Milk. Phenolic Compounds. Functional Food. Probiotics Viability.

\section{Introdução}

Segundo especialistas da Food and Agriculture Organization of the United Nations / World Health Organization, probióticos são micro-organismos vivos que quando administrados em quantidades adequadas conferem benefícios à saúde do hospedeiro (FAO/WHO, 2002). Diversos efeitos são associados ao consumo de probióticos, tais como: alívio da constipação, modulação da microbiota intestinal pela redução de agentes biológicos causadores de doenças gastrointestinais, estímulo do sistema imune, promoção de homeostase, entre outros (ANTUNES et al., 2007).

Os probióticos estão presentes em diversos produtos alimentícios, sendo que alguns alimentos são considerados veículos ideais para chegada desses micro-organismos ao trato gastrointestinal humano, graças ao seu efeito protetor sobre cepas probióticas durante sua passagem até o local principal de ação, o cólon (ROLIM et al., 2014). O leite fermentado consiste em boa matriz alimentar para incorporação de probióticos, pois permite a manutenção e sobrevivência de muitas das cepas probióticas que são conhecidas.

A adição de sucos de frutas em leites fermentados probióticos tem sido uma tendência de mercado, uma vez que tende a aumentar o potencial funcional destes produtos. Estudos demonstram o poder antioxidante de frutas, tais como: a romã 
(Punica granatum, L.), atribuído à presença de substâncias com capacidade oxirredutora como os compostos fenólicos (JARDINI; MANCINE FILHO, 2007), sendo que estes apresentam também ação anti-inflamatória (ROSS et al., 2005). Tais substâncias são de extrema importância para o metabolismo humano, especialmente, em situações nas quais a homeostase está prejudicada, o que ocorre com frequência durante a prática intensa de exercícios físicos, como a produção excessiva de espécies reativas do oxigênio. Estes compostos geram uma série de alterações nas membranas celulares, através da oxidação e dano dos lipídios, proteínas e DNA, favorecendo o aparecimento de doenças que podem causar lesões nas fibras musculares (CRUZ et al., 2017). Animais que fizeram ingestão de suco de romã (suspensão aquosa de romã em pó) apresentaram um aumento no nível de anticorpos e, também, da inibição na migração leucocitária (ROSS et al., 2005), mostrando potencial do uso da romã na redução da resposta inflamatória.

A romã possui também compostos com atividade antimicrobiana, de importância para a sobrevivência da planta e de grande interesse contra patógenos humanos. Um estudo realizado pelo grupo de pesquisa analisou oito alimentos/ condimentos (sálvia, pimenta branca, polpa da romã, casca da romã, curry, gengibre, noz moscada e canela) determinando seus potenciais antioxidantes e antimicrobianos (CHAVES, 2014). Todos os alimentos analisados demonstraram potencial antioxidante. Ao analisar a propriedade antimicrobiana pelo teste de difusão em disco os resultados mostraram que esses alimentos foram capazes de reduzir o crescimento de Staphylococcus aureus (casca da romã $>$ noz moscada $>$ polpa da romã $>$ canela $>$ curry $>$ gengibre $>$ sálvia $>$ pimenta branca) e Bacillus cereus (casca da romã $>$ noz moscada $>$ pimenta branca $>$ canela $>$ sálvia $>$ polpa da romã $>$ gengibre $>$ curry), com valores semelhantes ou superiores ao observado para o controle ampicilina $(p<0,01)$. Entretanto, esta característica é especialmente indesejável quando o micro-organismo em questão é um probiótico. Desta forma, a susceptibilidade da cepa em questão deve ser avaliada. Em estudos preliminares com cepas probióticas isoladas de produtos comerciais não foi observada redução importante da viabilidade de Lactobacillus casei Shirota e Lactobacillus casei defensis, com emprego dos mesmos alimentos/condimentos (CHAVES, 2014).

Além de sobreviver a todos estes componentes advindos do próprio alimento, os probióticos devem ser capazes de sobreviver também à digestão humana. A digestão é um processo, no qual nutrientes imobilizados dentro de estruturas celulares dos alimentos e que não podem ser absorvidos diretamente, sofrem ação dos sucos digestivos, contendo enzimas, que são responsáveis por hidrolisar essas macromoléculas, modificandoas em moléculas menores passíveis de sofrer absorção, e serem aproveitadas pelo organismo humano (SILVA JR., 2009). Portanto, a sobrevivência dos probióticos ao trato digestório é um desafio na elaboração de produtos da indústria alimentícia, já que existem diversas condições desfavoráveis que impactam na viabilidade destes, como: o suco gástrico, a bile, a secreção pancreática, e o peristaltismo (BERNUCCI et al., 2017). A sobrevivência de uma cepa está principalmente relacionada com questões intrínsecas do micro-organismo. Alguns estudos comprovam a capacidade de Bifidobacterium animalis (HN019) de resistir à bile e ao $\mathrm{pH}$ ácido de testes de digestão in vitro, sendo considerado um probiótico de alto potencial (SOUSA, 2011; KLINDT-TOLDAM, 2016). Entretanto, a matriz alimentar na qual esse está inserido também tem um grande papel na proteção destas bactérias durante o processo digestivo (ANTUNES; CAZETTO; ABOLINI, 2005; MARTÍN-DIANA et al., 2003).

Considerando o exposto, o objetivo do presente trabalho foi avaliar a resistência à digestão simulada de cinco cepas probióticas adicionadas individualmente em leite fermentado, contendo suco de romã, visando escolher a cepa de melhor desempenho para o desenvolvimento de uma bebida esportiva.

\section{Material e Métodos}

\subsection{Culturas microbianas}

As culturas microbianas testadas na bebida esportiva desenvolvida foram: Lactobacillus casei (BGP93), Lactobacillus rhamnosus (SP1) e Lactobacillus acidophilus (LA3); Bifidobacterium animalis subsp. lactis (BB12). Como cultura starter foi utilizado Streptococcus thermophilus (TA072).

\subsection{Estudo de condições seletivas de cultivo de probióticos}

As condições de cultivo foram avaliadas buscando-se obter contagens seletivas dos probióticos na presença da cultura starter (S. thermophilus) para desenvolvimento da bebida. Para isso foram empregados os meios TOS-Proprionate agar (para a cultura do gênero Bifidobacterium ssp.) e DeMan, Rogosa e Sharpe (MRS) (para a cultura de Bifidobacterium ssp. e Lactobacillus ssp.) com e sem adição de antibióticos e outros agentes inibidores, conforme normas técnicas da ISO 29981/ IDF 220; ISO 20128:2006; ISO 27205:IDF 149 (2010) e IDF 411/2007. A incubação foi realizada em anaerobiose sendo utilizados jarra e gás gerador de anaerobiose (Anaerogen, Oxoid) a $37^{\circ} \mathrm{C}$ por 72 horas.

As contagens foram realizadas em duplicata e realizados três ensaios independentes. Os resultados expressos em $\log$ UFC.mL-1. A taxa de recuperação das culturas (TR) foi calculada segundo Faleiro et al. (2015), utilizando as contagens no meio de referência (CMR) e nos meios seletivos (CMS), incluindo suas variações ( $\mathrm{TR}=\mathrm{CMS} / \mathrm{CMR} * 100)$.

Para contagem da cultura starter $S$. thermophilus foram utilizados os meios ST agar e M17 (meios seletivos para essa cultura) com incubação em aerobiose a $37^{\circ} \mathrm{C}$ por $48 \mathrm{~h}$ e os resultados expressos em log UFC. $\mathrm{g}^{-1}$.

\subsection{Teste de viabilidade dos probióticos expostos a suco de romã}

A viabilidade de cada um dos probióticos foi avaliada de duas formas: por teste in vitro com exposição das cepas à 
solução diluente estéril adicionada de suco de romã, contendo 2,625 mmol de polifenóis da fruta; e por teste in situ com preparo de leites fermentados adicionados de suco de romã, contendo os probióticos individualmente adicionados.

Para teste in vitro foram adicionados ao suco de romã $10 \mathrm{~mL}$ dos probióticos liofilizados previamente aliquotados em leite (aproximadamente $8 \log$ UFC.mL ${ }^{-1}$ ), com correção do volume para $100 \mathrm{~mL}$ com solução diluente padrão. As amostras foram armazenadas a $10{ }^{\circ} \mathrm{C}$ e feitas contagens do probiótico nos tempos $0,120 \mathrm{~min}, 5$ dias e 20 dias em meio MRS e incubadas em anaerobiose a $37^{\circ} \mathrm{C}$ por $72 \mathrm{~h}$.

Para teste in situ foram obtidos leites fermentados com suco de romã adicionados de cada um dos probióticos em avaliação. Os leites fermentados foram armazenados a $10^{\circ} \mathrm{C}$ e feitas contagens do probiótico nos tempos 0, 14 dias e 28 dias em meio MRS acidificado (Lactobacillus ssp.) e TOS-MUP (B. animalis) com incubação em anaerobiose a $37^{\circ} \mathrm{C}$ por $72 \mathrm{~h}$.

\subsection{Formulação da bebida probiótica esportiva}

A bebida probiótica esportiva foi produzida com a seguinte composição: $85 \%$ de leite desnatado (leite em pó reconstituído a $6 \%$ ), 3,5\% de concentrado proteico do soro de leite, $4 \%$ de maltodextrina e $6,4 \%$ de frutose. A esta base foi aplicada tratamento térmico por $85{ }^{\circ} \mathrm{C}$ por 3-5 segundos, seguido de resfriamento até $45^{\circ} \mathrm{C}$ e adição da cultura probiótica $(0,5 \mathrm{~g})$ e da cultura starter $S$. thermophilus $(0,01 \mathrm{~g})$. A mistura base foi fermentada a $45{ }^{\circ} \mathrm{C}$ até ser atingido $\mathrm{pH} 4,6 \pm 0,1$. Em seguida, foram adicionados $140 \mathrm{~mL}$ de suco de romã (obtido diretamente da fruta por despolpador e previamente pasteurizado a $92^{\circ}$ por $30-40$ segundos), $1,5 \mathrm{~g}$ de conservante sorbato de potássio e $0,22 \%$ de emulsão de frutas vermelhas (Givaudan, Sweet Mix). Em todas as etapas, os ingredientes foram homogeneizados utilizando agitador mecânico (Tecnal - TE 139). A bebida probiótica foi porcionada em volumes de $140 \mathrm{~mL}$ em garrafas higienizadas de polipropileno de alta densidade, com tampas rosqueáveis e traváveis, e armazenadas sob refrigeração a $10^{\circ} \mathrm{C}$ por 28 dias.

\subsection{Digestão simulada}

Para simulação da digestão gastrointestinal foi utilizado protocolo descrito por Buriti et al. (2010). As amostras da bebida esportiva foram diluídas em solução de $\mathrm{NaCl}$ 0,85\%, nas proporções de $25 \mathrm{~g}$ de amostra para $225 \mathrm{ml}$ de solução $\mathrm{NaCl}$. O experimento foi conduzido para cada amostra em triplicata, sendo preparados três frascos para cada fase da digestão gastrointestinal, totalizando nove frascos por ensaio, contendo $10 \mathrm{~mL}$ de amostra em cada (BURITI et al., 2010).

A simulação da digestão foi realizada utilizando as soluções gástricas, contendo pepsina $(0,3 \mathrm{~g} / \mathrm{L})$ e lipase $(0,9 \mathrm{~g} / \mathrm{L})$ e solução entérica, contendo bile bovina $(10 \mathrm{~g} / \mathrm{L})$ e pancreatina (1 g/L) diluídos em tampão fosfato de sódio (estéril).

A Fase Gástrica consistiu na adição da solução gástrica às amostras, com ajuste de $\mathrm{pH}$ entre 2,0 e 2,5 com ácido clorídrico $(\mathrm{HCl} 1 \mathrm{~N})$. Após ajuste do $\mathrm{pH}$, as amostras foram dispostas em um banho-maria metabólico tipo Dubnoff a $37^{\circ} \mathrm{C}$, em agitação constante a 150 RMP, durante 2 horas (BURITI et al., 2010).

Após fase gástrica e separação de três frascos para análise, foram adicionados aos demais a solução entérica, consistindo na Fase Entérica 1, com ajuste do pH entre os valores de 4,5 e 5,5. Os frascos foram mantidos em banho-maria e agitação por mais 2 horas, a $37^{\circ} \mathrm{C}$.

Após a Fase Entérica 1 e separação de três frascos para análise foi realizada nova adição de solução entérica nos frascos restantes, representando a Fase Entérica 2, até atingir pH entre 6,5 e 7,5. Os frascos foram novamente incubados por mais 2 horas em banho-maria a $37^{\circ} \mathrm{C}$, com agitação (BURITI et al., 2010).

\subsection{Determinação da viabilidade das culturas probióticas após digestão simulada}

A fim de determinar a viabilidade das culturas probióticas, ao término da digestão, foram realizadas diluições decimais das amostras adicionando-se $100 \mu \mathrm{L}$ da amostra em $900 \mu \mathrm{L}$ de água peptonada em microtubos até atingir todas as diluições desejadas. As diluições foram inoculadas em placa de Petri $(10 \mu \mathrm{L}$ drop plate), contendo meio de cultura MRS Agar acidificado e incubação em anaerobiose por 72 horas a $37^{\circ} \mathrm{C}$ (BURITI et al., 2010).

A viabilidade foi definida por meio do cálculo da Taxa de Sobrevivência de Probióticos (TS), utilizando a contagem do micro-organismo durante a digestão para cada fase (CMDD) e a contagem do micro-organismo sem a digestão (CMSD), adotando a seguinte fórmula: $\mathrm{TS}=\mathrm{CMDD} / \mathrm{CMSD}^{*} 100$. Os resultados foram submetidos a avaliação estatística utilizando a análise de variância one-way (ANOVA) e teste de Tukey, adotando $\mathrm{p}<0.05$. Todos os resultados foram analisados utilizando o software online SAS University Edition.

\subsection{Viabilidade durante armazenamento refrigerado}

A viabilidade dos probióticos na bebida foi acompanhada durante armazenamento refrigerado a $6{ }^{\circ} \mathrm{C}$ por 28 dias com análises semanais por plaqueamento, em meio de cultura MRS Agar acidificado, utilizando o método pour plate e incubação em anaerobiose (Anaerogen/Oxoid) por 72 horas a $37^{\circ} \mathrm{C}$.

\section{Resultados e Discussão}

Para o desenvolvimento de uma bebida esportiva com alto teor de probióticos e elevada sobrevivência ao processo de digestão foram inicialmente realizados estudos sobre as condições seletivas de cultivo deste probiótico.

Cada probiótico selecionado para teste foi semeado em diversos meios de cultura de referência e seletivos, a fim de se obter as contagens e taxas de recuperação correspondentes.

Para os cálculos de taxa de recuperação, o meio MRS sem acidificação e sem acréscimo de antibióticos foi empregado como o meio de referência para os probióticos. Para a cultura starter S. thermophilus foi adotado o meio M17 como referência. Os Quadros 1, 2 e 3 apresentam as contagens médias (log UFC/ml) de Lactobacillus, Bifidobacterium e Streptococcus thermophilus 
em diferentes meios seletivos e a respectiva taxa de recuperação.

Quadro 1 - Contagem média (log UFC.mL $\left.{ }^{-1}\right)$ de Lactobacillus em diferentes meios seletivos e respectiva taxa de recuperação (\%)

\begin{tabular}{|c|c|c|c|c|c|c|}
\hline \multirow{3}{*}{ Meio de cultura } & \multicolumn{6}{|c|}{ Micro-organismo } \\
\hline & \multicolumn{2}{|c|}{ L. casei (BGP93) } & \multicolumn{2}{|c|}{ L. acidophilus (LA3) } & \multicolumn{2}{|c|}{ L. rhamnosus (SP1) } \\
\hline & Media & TR & Media & TR & Media & TR \\
\hline MRS & $8,79 \pm 0,14^{\mathrm{A}, \mathrm{a}}$ & 100 & $8,59 \pm 0,42^{\mathrm{A}, \mathrm{a}}$ & 100 & $8,70 \pm 0,46^{\mathrm{A}, \mathrm{a}}$ & 100 \\
\hline MRS (A) & $8,77 \pm 0,30^{\mathrm{A}, \mathrm{a}}$ & 100,45 & $8,58 \pm 0,59^{\mathrm{A}, \mathrm{a}}$ & 102,30 & $8,46 \pm 0,03^{\mathrm{B}, \mathrm{a}}$ & 95,40 \\
\hline MRS (D) & $<1 \pm 0^{\mathrm{A}, \mathrm{b}}$ & 0 & $<1 \pm 0^{\mathrm{A}, \mathrm{b}}$ & 0 & $<1 \pm 0^{\mathrm{A}, \mathrm{b}}$ & 0 \\
\hline MRS (C) & $8,68 \pm 0,11^{\mathrm{A}, \mathrm{a}}$ & 96,60 & $8,38 \pm 0,21^{\mathrm{AB}, \mathrm{a}}$ & 102,10 & $8,30 \pm 0,14^{\mathrm{B}, \mathrm{a}}$ & 93,69 \\
\hline
\end{tabular}

Contagens em um mesmo meio de cultura, seguidas da mesma letra MAIÚSCULA indicam que não houve diferença estatística significante entre as cepas probióticas. Contagens seguidas da mesma letra MINÚSCULA indicam que para um mesmo probiótico não houve diferença estatística significante entre os meios de cultura utilizados. O MRS foi adotado como meio de referência para todos os probióticos, sendo assumida contagem total como $100 \%$ de recuperação das culturas. MRS (A) = acidificado (pH 5,2); MRS (D) = adicionado de dicloxacilina, cloreto de lítio e L-cisterna. MRS

(C) = adicionado de clindamicina

Fonte: Dados da pesquisa.

Quadro 2 - Contagem média (log UFC.mL $\left.\mathrm{mL}^{-1}\right)$ de Bifidobactéria em diferentes meios seletivos e respectiva taxa de recuperação $(\%)$

\begin{tabular}{|c|c|c|}
\hline \multirow{2}{*}{ Meio de cultura } & \multicolumn{2}{|c|}{ Micro-organismo } \\
\cline { 2 - 3 } & \multicolumn{2}{|c|}{ B. animalis (BB12) } \\
\cline { 2 - 3 } & Media & TR \\
\hline MRS & $9,93 \pm 0,12^{\mathrm{a}}$ & 100 \\
\hline MRS (A) & $9,89 \pm 0,14^{\mathrm{a}}$ & 99,65 \\
\hline MRS (D) & $<1 \pm 0^{\mathrm{b}}$ & 0 \\
\hline MRS (C) & $<1 \pm 0^{\mathrm{b}}$ & 0 \\
\hline TOS & $10,17 \pm 0,23^{\mathrm{a}}$ & 102,72 \\
\hline TOS (A) & $<1 \pm 0^{\mathrm{b}}$ & 0 \\
\hline TOS-MUP & $10,29 \pm 0,47^{\mathrm{a}}$ & 103,70 \\
\hline
\end{tabular}

Contagens seguidas da mesma letra MINÚSCULA indicam que para um mesmo probiótico não houve diferença estatística significante entre os meios de cultura utilizados. O MRS foi adotado como meio de referência para todos os probióticos, sendo assumida contagem total como $100 \%$ de recuperação das culturas. MRS (A) = acidificado (pH 5,2); MRS (D) = adicionado de dicloxacilina, cloreto de lítio e L-cisterna; MRS (C) $=$ adicionado de clindamicina; TOS $(\mathrm{A})=$ acidificado e TOS-MUP $=$ adicionado de mupirocina.

Fonte: Dados da pesquisa

Quadro 3 - Contagem média (log UFC.mL $L^{-1}$ ) Streptococcus thermophilus em diversos meios seletivos e respectiva taxa de recuperação $(\%)$

\begin{tabular}{|c|c|c|}
\hline \multirow{2}{*}{ Meio de cultura } & \multicolumn{2}{|c|}{ Micro-organismo } \\
\cline { 2 - 3 } & \multicolumn{2}{|c|}{ S. thermophilus (TA72) } \\
\cline { 2 - 3 } & Média & TR \\
\hline MRS & $6,62 \pm 0,80^{\mathrm{c}}$ & 59,53 \\
\hline MRS (A) & $<1 \pm 0^{\mathrm{d}}$ & 0 \\
\hline MRS (D) & $<1 \pm 0^{\mathrm{d}}$ & 0 \\
\hline MRS (C) & $<1 \pm 0^{\mathrm{d}}$ & 0 \\
\hline TOS & $9,02 \pm 1,00^{\mathrm{b}}$ & 81,11 \\
\hline TOS (A) & $<1 \pm 0^{\mathrm{d}}$ & 0 \\
\hline TOS-MUP & $<1 \pm 0^{\mathrm{d}}$ & 0 \\
\hline ST AGAR & $10,66 \pm 0,05^{\mathrm{a}}$ & 95,86 \\
\hline AGAR M17 & $11,12 \pm 0,04^{\mathrm{a}}$ & 100 \\
\hline
\end{tabular}

Contagens seguidas da mesma letra MINÚSCULA indicam que para um mesmo probiótico não houve diferença estatística significante entre os meios de cultura utilizados. O Agar M17 foi adotado como meio de referência para Streptococcus thermophilus sendo assumida contagem total como $100 \%$ de recuperação da cultura. MRS (A) = acidificado $(\mathrm{pH}$ 5,2); MRS (D) = adicionado de dicloxacilina, cloreto de lítio e L-cisterna;
MRS $(\mathrm{C})=$ adicionado de clindamicina; TOS $(\mathrm{A})=$ acidificado e TOSMUP = adicionado de mupirocina; ST Agar; Agar M17.

Fonte: Dados da pesquisa

Todos os probióticos testados no meio de referência (MRS) apresentaram contagens entre 7,4 log e 10,6 log UFC. $\mathrm{mL}^{-1}$, conforme observado nos Quadros 1 e 2.

Com relação às contagens de Lactobacillus (Quadro 1), em algumas variações do MRS não foi obtida recuperação das culturas, enquanto que em outros casos, essa recuperação foi equivalente ao meio de referência adotado (MRS).

Com relação à bifidobactéria (Quadro 2), os meios TOS e TOS+mupirocina proporcionaram taxa de recuperação maior do que as obtidas em meio de referência adotado (MRS), com contagens acima de 10 ciclos logarítmicos por mL. Por outro lado, o TOS acidificado inibiu por completo o crescimento da cepa.

Conforme apresentado no Quadro 3, a cultura $S$. thermophilus TA072 quando semeada nos meios ST ágar e M17 (indicados para contagem desta espécie) apresentou contagens de 10,6 e 11,1 log UFC.mL ${ }^{-1}$, respectivamente. A cultura apresentou crescimento em MRS e TOS (embora com taxas de recuperação de 59 e $81 \%$, respectivamente) e foi totalmente inibida em todas as variações avaliadas destes meios (adições de antibióticos ou acidificação).

Considerando estes dados, o meio MRS acidificado proporcionou boa taxa de recuperação (acima de 95\%) para todos os probióticos e representou eficiente meio de avaliação para o produto em desenvolvimento. Apesar da cultura B. animalis subp. lactis BB12, apresentar boa taxa de recuperação em MRS acidificado, também apresentou excelente recuperação no meio TOS suplementado com mupirocina, acima dos valores encontrados em MRS acidificado. Entretanto, não houve diferença estatisticamente significativa entre as contagens desta cultura em MRS e TOS ou TOS+MUP.

Faleiro et al. (2015) utilizaram o MRS como padrão e obteve contagens de bifidobactéria sempre acima de 8,0 $\log$ UFC.mL $L^{-1}$. Dave e Shah (1996) mostraram excelente recuperação de bifidobactéria no mesmo ágar. A adição de agentes específicos e/ou alteração de parâmetros, tais como: o $\mathrm{pH}$ pode melhorar a seletividade deste meio, propiciando 
o crescimento seletivo para bifidobactérias e inibindo o crescimento das bactérias ácido-lácticas. Entretanto, para algumas espécies, estas adições podem ser inibitórias, como foi o caso da adição de dicloxacilina neste trabalho. A dicloxacilina pertence ao grupo das penicilinas resistentes a penicilinases, que atuam na parede celular de bactérias provocando sua lise e tem sido indicada como antibiótico não inibitório de aproximadamente 35 linhagens de bifidobactérias (MURRAY et al. 2000). Para Lima et al. (2009), a adição de dicloxacilina ao MRS $(2 \mu \mathrm{g} / \mathrm{mL})$ inibiu o crescimento de bactérias starters do iogurte, mas não alterou a capacidade da bifidobactéria de crescer neste meio (LIMA et al., 2009). Semelhantemente, Sozzi et al. (1990) também utilizaram meios de cultura adicionado de $2 \mu \mathrm{g} / \mathrm{mL}$ dicloxacilina para inibir as principais linhagens de Lactobacillus e Streptococcus presentes em leites fermentados.

Determinados os parâmetros para contagem e seletividade dos probióticos selecionados, a sobrevivência desses microorganismos frente ao suco de romã foi avaliada, uma vez que o mesmo apresenta compostos com grande atividade antimicrobiana (KHARCHOUFI et al., 2018).

Para avaliar se o suco de romã inibiria culturas probióticas foi proposta uma triagem entre as cepas, conduzidas de duas maneiras distintas: por meio da adição direta das culturas isoladas em solução salina adicionada de suco de romã e em leite fermentado ambos com a mesma concentração de fenólicos totais $(2,62 \mathrm{mM})$. Os resultados obtidos das análises microbiológicas em solução diluente estéril e leite fermentado estão expressos nas Figuras 1 e 2.

Figura 1 - Teste de viabilidade de probióticos (log UFC.mL $\left.L^{-1}\right)$ em solução salina a $0,9 \%$ adicionada de suco de romã $(2,62 \mathrm{mM}$ fenólicos totais) pelo período de 20 dias

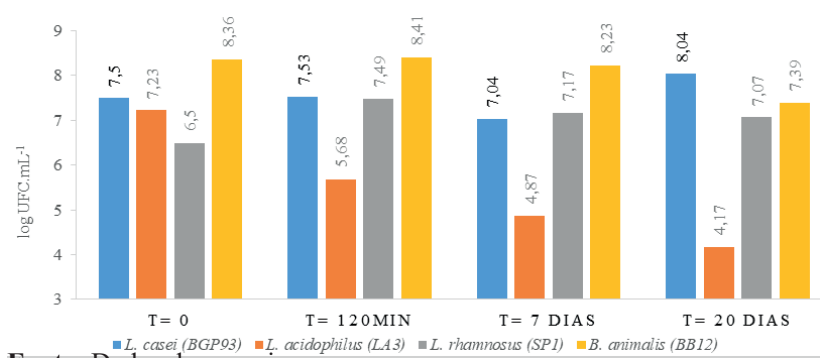

Fonte: Dados da pesquisa.

Figura 2 - Teste de viabilidade de probióticos (log UFC.mL $\left.\mathrm{mL}^{-1}\right)$ em leite fermentado adicionado de suco de romã $(2,62 \mathrm{mM}$ fenólicos totais) pelo período de 28 dias

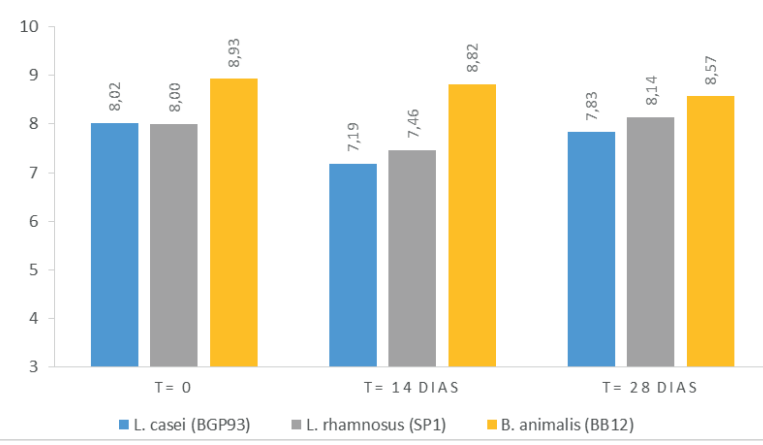

Fonte: Dados da pesquisa.

Todas as cepas de Lactobacillus foram cultivadas em MRS acidificado ( $\mathrm{pH} 5$,2). Para Bifidobacterium (BB12), foi usado TOS+MUP no cultivo.

No teste in situ foi observado que todas as culturas apresentaram comportamento semelhante e não foram inibidas pelo suco de romã, com exceção do L. acidophilus LA3, que apresentou decréscimo de 7,23 log UFC.mL $\mathrm{m}^{-1}(\mathrm{t}=0)$ para 4,17 UFC. $\mathrm{mL}^{-1}$ ( $\mathrm{t}=20$ dias). Isso pode ser explicado pela grande atividade antimicrobiana presente na romã (CHAVES, 2014), que poder ter atuado contra esta cepa. Esta atividade antimicrobiana é vista como positiva, quando são inibidos patógenos e micro-organismos deterioradores de produtos, mas indesejável quando se trata da inibição de culturas probióticas adicionadas, como observado com a cultura LA3.

Dada a baixa sobrevivência do L. acidophilus LA3 no teste in vitro, essa cepa não foi empregada para o teste posterior, ou seja, na bebida esportiva. Desta forma, apenas três culturas foram utilizadas no teste in situ.

Conforme apresentado na Figura 2, a cultura B. animalis BB12 apresentou as mais altas contagens entre todos os probióticos (acima de 8,5 $\log$ UFC. $\mathrm{mL}^{-1}$ ) durante todo o período de armazenamento ( $\mathrm{n}=28$ dias). Entretanto, os demais probióticos testados também apresentaram boa manutenção das contagens na matriz alimentar proposta durante o tempo de armazenamento avaliado, consistindo em opção viável para incorporação no produto em desenvolvimento.

A bebida esportiva foi, portanto, desenvolvida com três variações, utilizando cada uma das três culturas restantes separadamente, a saber: L. casei (BGP93), L. rhamnosus (SP1), B.animalis (BB12). Após a formulação das bebidas, foi avaliada a viabilidade de cada cepa nesta matriz após processo de digestão simulada.

A Figura 3 compara a sobrevivência em porcentagem de cada probiótico avaliado, em sua respectiva fase do ensaio in vitro.

Figura 3 - Taxa de Sobrevivência (\%) dos probióticos Lactobacillus casei (BGP93), Lactobacillus rhamnosus (SP1) e Bifidobacterium animalis subsp. lactis (BB12) em bebida esportiva fermentada

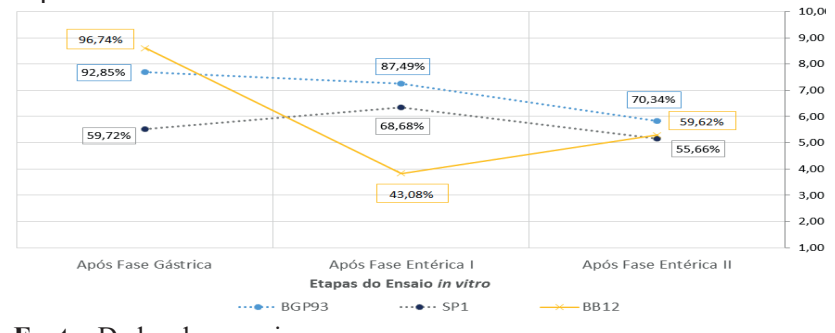

Fonte: Dados da pesquisa.

Os resultados da viabilidade dos probióticos apresentados na Figura 3 mostram que houve uma diminuição das contagens de B. animalis BB12 e L. casei BGP93 da fase gástrica para a entérica II, já que as soluções de enzimas e a agitação constante desempenham papel extremamente 
agressivo às células bacterianas. Entretanto, a Lactobacillus rhamnosus SP1 apresentou taxa de sobrevivência semelhante entre as fases da digestão. Além disso, observou-se para essa cepa uma elevação da taxa de sobrevivência na fase entérica I comparado à fase gástrica, indicando que o $\mathrm{pH}$ mais próximo da neutralidade favoreceu a recuperação parcial dos danos causados na fase anterior (MENEZES et al., 2013; BOTELHO et al. 2015).

\section{Conclusão}

$\mathrm{Na}$ contagem seletiva dos probióticos avaliados foi observado que o MRS acidificado proporcionou crescimento seletivo para as cepas do gênero Lactobacillus e na presença do starter $S$. thermophilus TA072. O meio TOS-MUP se apresentou seletivo para a B. animalis BB12 na presença da cultura starter e propiciou taxa de recuperação desta cepa superior ao encontrado no cultivo em MRS e MRS acidificado.

Os testes de sobrevivência do probiótico na presença de suco de romã mostraram que as culturas B. animalis BB12, $L$. casei BGP93 e L. rhamnosus SP1 não apresentaram inibição pelos compostos presentes na romã, ao contrário da cultura $L$. acidophilus LA-3.

A cultura L. casei BGP93 apresentou maior taxa de sobrevivência durante digestão simulada, quando comparado aos demais probióticos avaliados nesta pesquisa, sendo indicada para elaboração de bebida esportiva probiótica adicionada de suco de romã.

\section{Agradecimentos}

A FAPESP (2015/07229-7 e 2015/13972-6), FAEPEX (convênio 519.292) e CAPES (código 001).

\section{Referências}

ANTUNES, A.E.C.; CAZETTO, T.F.; ABOLINI, H.M. Viability of probiotic micro-organisms during storage, postacidification and sensory analysis of fat-free yogurts with added whey protein concentrate. Int. J. Dairy Technol., v.58, n.3, p.169-173, 2005. doi: $10.1111 / \mathrm{j} .1471-0307.2005 .00203 . \mathrm{x}$

ANTUNES, A.E.C. et al. Probióticos: agentes promotores de saúde. Rev. Soc. Bras. Aliment. Nutr., v.32, n.3, p.113-132, 2007.

ASHRAF, R.; SHAH, N.P. Selective and differential enumerations of Lactobacillus delbrueckii subsp. bulgaricus, Streptococcus thermophilus, Lactobacillus acidophilus, Lactobacillus casei and Bifidobacterium spp. in yoghurt: a review. Int. J. Food Microbiol., v.149, n.3, p.94-208, 2011. doi: 10.1016/j. ijfoodmicro.2011.07.008

BERNUCCI, B.S.P. et al. Effect of microencapsulation conditions on the viability and functionality of Bifidobacterium longum $5^{1 A}$. Food Scie. Technol., v.80, p.341-347, 2017. doi: 10.1016/j. lwt.2017.02.036

BOTELHO, L.G. et al. Resistência in vitro de bactérias ácido láticas isoladas de iogurtes brasileiros ao suco gástrico e sais biliares. Rev. Cient. Univiçosa, v.7, n.1, p.1-6, 2015.

BURITI, F.C.A.; CASTRO, I.A.; SAAD, S.M I. Viability of Lactobacillus acidophilus in synbiotic guava mousses and its survival under in vitro simulated gastrointestinal conditions. Int. J. Food Microbiol., v.137, p.121-129, 2010. doi: 10.1016/j. ijfoodmicro.2009.11.030

CHAVES, F.M. et al. Evaluation of antimicrobial and antioxidant activity of bioactive compounds present in vegetables and spices consumed in Brazil. In: OXYGEN CLUB OF CALIFORNIA WORLD CONGRESS 2014, Davis, California. Oxygen Club of California World Congress 2014, p.77, 2014.

CRUZ, R.M.O. et al. Consumo de antioxidantes para práticas de exercícios físicos. Electr. J. Collection Health, v.5, p. 199-202, 2017.

DAVE, R.I.; SHAH, N.P. Evaluation of media for selective enumeration of Streptococcus thermophilus, Lactobacillus delbrueckii ssp bulgaricus, Lactobacillus acidophilus and bifibobacteria. J. Dairy Scie., v.79, n.9, p.1529-1536, 1996 doi: 10.3168/jds.S0022-0302(96)76513-X

FALEIRO, L.R. et al. Evaluation of culture media for selective enumeration of Bifidobacterium spp. in combination with different strains of Streptococcus thermophilus isolated from commercial yogurt starter cultures. Afr. J. Microbiol. Res., v.9, p.373-381, 2015. doi: 10.5897/AJMR2014.7269

FAO/WHO. Food and Agriculture Organization of the United Nations. World Health Organization. In: WORKING GROUP REPORT ON DRAFTING GUIDELINES FOR THE EVALUATION OF PROBIOTICS IN FOOD. London, Ontario, Canada, 2002.

ISO 20128:2006 Milk products: enumeration of presuntive Lactobacillus acidophilus on a selective medium - Colony-count technique at $37^{\circ} \mathrm{C}$.

ISO 29981/IDF 220 Milk products - Enumeration of presuntive bifidobacteria - Colony count technique at $37^{\circ} \mathrm{C}$.

ISO 27205/IDF 149 (2010) Fermented milk products - Bacterial starter cultures - Standard of identity, 2010.

IDF 411/2007 Selective enumeration of Bifidobacterium in dairy products: development of a standard method.

JARDINI, F.A.; MANCINI FILHO, J. Avaliação da atividade antioxidante em diferentes extratos da polpa e sementes da romã (Punica granatum, L.). Rev Bras. Ciênc. Farm., v.43, n.1, p.137147, 2007. doi: 10.1590/S1516-93322007000100017

KHARCHOUFI, S. et al. Antimicrobial and antioxidant features of 'Gabsi' pomegranate peel extracts. Ind. Crops Products, v.111, p.345-352, 2018. doi: 10.1016/j.indcrop.2017.10.037

KLINDT-TOLDAMA, S. et al. Survival of Lactobacillus acidophilus NCFM® and Bifidobacterium lactis HN019 encapsulated in chocolate during in vitro simulated passage of the upper gastrointestinal tract. LWT - Food Scie. Technol., v.74, p.404-410, 2016. doi :10.1016/j.lwt.2016.07.053

LIMA, K.G.D.C. et al. Evaluation of culture media for enumeration of Lactobacillus acidophilus, Lactobacillus casei and Bifidobacterium animalis in the presence of Lactobacillus delbrueckii subsp bulgaricus and Streptococcus thermophilus. LWT - Food Scie. Technol., v.42, n.2, p.491-495, 2009. doi: 10.1016/j.lwt.2008.08.011

MARTÍN-DIANA, A.B. et al. Development of a fermented goat's milk containing probiotic bacteria. Int. Dairy J., v.13, n.10, p.827-833, 2003. doi: 10.1016/S0958-6946(03)00117-1

MENEZES, C.R. et al. Microencapsulação de probióticos: avanços e perspectivas. Ciênc. Rural, v.43, n.7, p.1309-1316, 2013

MURRAY, M.A. Cereal production and processing. Ancient Egyptian Materials Technol., v.2, p.505-536, 2000.

ROLIM, F.R.L. et al. Avaliação in Vitro do Potencial Probiótico de 
Queijo Coalho Caprino adicionado de Lactobacillus rhamnosus. In: Anais do $12^{\circ}$ Congresso Latinoamericano de Microbiologia e Higiene de Alimentos - MICROAL 2014 [Blucher Food Science Proceedings, n.1, v.1]. São Paulo: Blucher, 2014.

ROSS, R.P. et al. Overcoming the technological hurdles in the development of probiotic foods. J. Appl. Microbiol., v.98, p.14101417, 2005. doi: 10.1111/j.1365-2672.2005.02654.x

SILVAJR,A.S. Interações químico-fisiológicas entre acidificantes, probióticos, enzimas e lisofosfolipídios na digestão de leitões. Rev. Bras. Zootec., v.38, p.238-245, 2009. doi: 10.1590/S151635982009001300024

SOUSA, A.L.O.P. Viabilidade de Bifidobacterium animalis subsp. lactis HN019 em fórmulas infantis probióticas durante o armazenamento a $4^{\circ}$ C. São Paulo: USP, 2011.
SOZZI, T. et al. Use of dicloxacillin for the isolation and counting of Bifidobacteria from dairy products. Le Lait, v.70, n.4, p.357361, 1990. doi: 10.1051/lait:1990427

THITARAM, S.N.; SIRAGUSA, G.R.; HINTON, A. Bifidobacterium-selective isolation and enumeration from chicken caeca by a modified oligosaccharide antibiotic-selective agar medium. Letters Appl. Microbiol., v.41, n.4, p.355-360, 2005. doi: 10.1111/j.1472-765X.2005.01765.x

VAN DE CASTEELE, S. et al. Evaluation of culture media for selective enumeration of probiotic strains of Lactobacilli and Bifidobacteria in combination with yoghurt or cheese starters. Int. Dairy J., v.16, n.12, p.1470-1476, 2006. doi: 10.1016/j. idairyj.2005.12.002 